\title{
FORMAÇÃO E EDUCAÇÃO POPULAR NO CAMPO ENTRE A IGREJA CATÓLICA E ESTADO (1954-1964)
}

Leila de Menezes Stein ${ }^{\mathrm{i}}$

\begin{abstract}
RESUMO
No Brasil a Igreja Católica teve papel relevante para a construção da cidadania, educação e formação das camadas populares rurais da população. Estudamos, nesse artigo, essa participação e contribuição na década de 60 , colocando em destaque a forte ponderação que assumiria a questão da reforma agrária. A Igreja Católica seria um dos principais atores nas campanhas de sindicalização e de educação de base e sofreria grandes tensões e conflitos internos que a dividiriam entre aqueles que buscavam a "libertação dos oprimidos" e os que lutavam por reformas sem alterar a "ordem social". Recupera-se a trajetória de implantação de diversos programas católicos de formação sindical e de fundação de sindicatos. Utilizamos a metodologia histórica e recuperamos a voz de seus autores através de entrevistas com sindicalistas, com advogados, autoridades eclesiásticas e militantes populares.

Palavras-chave: Movimento Circulista; formação sindical; Ação Popular; Reforma Agrária
\end{abstract}

\section{POPULAR EDUCATION AND TRAINING IN THE FIELD BETWEEN THE CATHOLIC CHURCH AND STATE (1954-1964)}

\begin{abstract}
In Brazil, the Catholic Church has an important role in the construction of citizenship, education and training the rural lower classes of the population. Studied in this article, this participation and contribution in the 60s, by highlighting the strong weighting would take the issue of land reform. The Catholic Church was a major player in unionization campaigns and basic education and suffered great tensions and internal conflicts that divide between those who sought the "liberation of the oppressed" and those who fought for reforms without changing the "social order". This paper recovers the trajectory of implementation of various programs of Catholic union formation and foundation of unions. We use historical methodology and retrieve the voice of the authors through interviews with trade unionists, lawyers, church authorities and militants popular.

Keywords: Union formation, agrarian reform, Movimento Circulista, Ação Popular.
\end{abstract}

\section{Apresentação}

A exposição que se segue, versa sobre questões do desenvolvimento do projeto sindical para os trabalhadores agrícolas no Brasil. Analiso, para tanto, em seus grandes traços, alguns dos principais projetos de intervenção da Igreja e de suas áreas próximas. De início, tem-se como fato marcante no percurso de tais projetos, a abertura de uma política de negociações por parte do Estado brasileiro, que passaria, lentamente, a reconhecer a legitimidade dos movimentos camponeses e dos trabalhadores rurais por terra e por direitos. Sugerimos que a Igreja Católica e o Estado brasileiro traçariam acordos e planos para a fundação e o reconhecimento de sindicatos rurais.

O contraponto dessa política trabalhista que então se engendrava, estaria, sem dúvida, na afirmação do personagem político camponês. Conquistando esse novo 
espaço político e sofrendo muitas mistificações, o trabalhador do campo seria o principal envolvido pelas tentativas de políticas de reformas e de suas retóricas (MEDEIROS, 1982). Por isso mesmo, talvez, a questão do grau de intensidade da reforma desejada fosse um divisor de águas importante para as principais tendências políticas que intervieram na sindicalização.

Preliminarmente, pode-se afirmar que tais propostas tenderam a organizar-se em torno de três grandes linhas de intervenção, demarcadas por alianças e articulações estabelecidas nesse processo de construção e consolidação do sindicato. Localizamos três projetos de intervenção da Igreja Católica. O primeiro correspondia a uma tática do "sindicato a todo custo", ou seja, ter o controle da estrutura sindical. Particularmente ativa nos anos de 1961 e 1962, teria a adesão, especialmente, das seguintes áreas de trabalho sindical: "plano da Diocese de Natal" de D. Eugênio Sales, no Rio Grande do Norte; Serviço de Orientação Rural de Pernambuco - SORPE - liderado por Padre Paulo Crespo; plano de educação popular de Sergipe, sediado na diocese de Aracaju presidida por D. José Távora; projeto da Confederação Nacional dos Círculos Operários - CNCO- e Frente Agrária Gaúcha - FAG - ligada à diocese de Porto Alegre, com D. Vicente Scherer.

De todo modo, dois projetos repeliam-se polarmente e, como se sabe, em fins dos 50, cindem-se e acabariam por se tornar conflitantes, expressando-se em atrações fortes sobre o conjunto de seus trabalhos sociais. Cabe enunciar, de um lado, os trabalhos desenvolvidos pela Ação Popular - AP -, partido político originário da Ação Católica e da Juventude Universitária Católica - JUC - e que teve uma intervenção importante no Movimento de Educação de Base - MEB. E de outro lado, a atuação em que se empenharia o Movimento Circulista $e$ a Confederação Nacional dos Círculos Operários.

Dividindo-se entre adesão ou não à tese da necessidade de reformas estruturais e democratização do acesso à terra, a Igreja Católica e suas cisões internas tinham, evidentemente, no estado brasileiro e sua política trabalhista, uma referência primordial. O "Plano de Emergência" da Conferência Nacional dos Bispos do Brasil, aprovado em 1962, indica um tipo de aliança e acordos com o Governo Parlamentarista de João Goulart. A Ação Popular, um ano mais tarde, atuaria dentro de uma "política de frente única" com o Partido Comunista Brasileiro, o que a levava, também, a estar próxima ao Governo Presidencialista de Goulart.

Neste artigo, utiliza-se uma base documental extensa e detalhada para o estudo do circulismo, o que até não seria de todo repreensível, posto que quase não existem textos sociológicos disponíveis. Quanto ao estudo da Ação Popular e do Movimento de Educação de Base, utiliza-se, quase que exclusivamente, depoimentos de ex militantes, contidos em livros já publicados.

Uma última questão, optamos pelo critério cronológico para apresentar os trabalhos sindicais da Igreja. Esse procedimento corresponde a uma sugestão de que se tratava de uma matriz doutrinária unitária que se fragmentaria em muitas direções. Supomos, portanto, a existência de um debate mãe sobre a intervenção política na questão social. De todo modo, seus militantes e suas biografias se cruzam na história real que constroem. Passa-se, a seguir, a descrição do tipo de intervenção de cada uma das três tendências indicadas. Tal estudo versa sobre: principais pontos doutrinários e alguns traços de suas estratégias de sindicalização.

\section{Conferência Nacional dos Bispos e os Sindicatos Rurais}

A partir dos anos 50, a Igreja se envolveria em trabalho social junto às 
camadas populares no campo (MARTINS, 1981). Num primeiro bloco de intervenções, se situavam, assim, posições e tendências políticas de caráter laico e que ganhariam força a partir da constituição do Movimento de Educação de Base - MEB. Tem-se um espectro de posições, que se formava no interior de suas diversas entidades, como por exemplo, aquelas que se desenvolveram a partir do crescimento da Juventude Estudantil Católica - JEC- e da Juventude Universitária Católica - JUC.

Outro bloco dentro da Igreja é o Movimento Circulista, entidade voltada para os trabalhadores que se reorganizaria através da Confederação Nacional dos Círculos Operários e passaria a ser um pólo político importante de atração de trabalhos sociais e doutrinários de algumas dioceses.

No entanto, conformando um terceiro bloco, tais trabalhos laicos também estavam articulados ao Movimento de Educação de Base e à Ação Católica, como por exemplo, seriam os trabalhos da Diocese de Natal com a equipe sindical de Julieta Calasaens as iniciativas sindicais como as dos párocos Padre Antônio Mello e Padre Paulo Crespo, párocos dos municípios de Cabo e de Jaboatão, respectivamente, em Pernambuco.

De todo modo, logo após a posse de João Goulart, em 1961, na presidência da República, a Igreja lançaria uma campanha específica de sindicalização rural, por orientação da Conferência Nacional dos Bispos. Muitas dioceses responderam a esse apelo, ou reorientando seus trabalhos assistências no sentido do sindicato, ou criando equipes e grupos com tais objetivos específicos. Algumas orientações episcopais formariam outros movimentos pela sindicalização. Tais seriam as frentes agrárias, entre as quais se destacaria, pela sua dinâmica, a Frente Agrária Gaúcha -FAGfundada em 1961, por iniciativa de D. Vicente Scherer, arcebispo de Porto Alegre.

Situada, brevemente, a questão sindical colocada na pauta política do governo, passamos ao desenvolvimento das questões doutrinárias no interior da Igreja.

\section{Movimento Circulista}

O movimento circulista teria suas origens, nos anos 30, numa proposta prestada pela Igreja Católica para organização do movimento operário. Situada num quadro doutrinário da Igreja Católica Internacional, tal proposta tinha enquanto princípios organizativos gerais as concepções da Encíclica Rerum Novarum, do Papa Leão XIII, que preconizavam a necessidade de evangelização dos sindicatos, ou seja, pontualmente, propunha-se a formação de entidades cristãs de cunho econômico e social que pudessem responder ao avanço das trade unions e das propostas sindicais de cunho socialista.

No Brasil, a proposta circulista aglutinaria setores sociais dispersos dentro da Igreja e que articulavam, também, a formação de sindicatos cristãos. Entre as principais merecem ser citadas as contribuições de Tristão de Ataíde, no Rio de Janeiro, que lançaria a proposta de fundação da Confederação Nacional de Operários Católicos CNCO, em 1931. Essa confederação teria como "assistente eclesiástico" o padre Leopoldo Brentano, pároco da cidade de Pelotas no Rio Grande do Sul, que projetava, também, uma cristianização do movimento operário, o que significava uma intervenção especificamente cristã naquele movimento.(REYMOND, 1961).

Interessante observar que o circulismo não nasceria distante do Estado brasileiro. Ao contrário, seus adeptos concordaram com a orientação geral da política traçada para a força de trabalho, reverenciando a criação do Ministério do Trabalho Indústria e Comércio, em 1931. Identificavam-se, também, com a formulação de leis sociais, entendidas enquanto uma "solução pacífica para questão do trabalho"

Durante todo o período que antecedeu a ditadura do Estado Novo, em 1937, 
lutaram em todos os fóruns de debate politico pela defesa do sindicato cristão. Ainda assim tal posição não conseguiria construir um consenso sobre sua necessidade, e o princípio oficializante da estrutura sindical brasileira rejeitaria sindicatos políticos ou religiosos.

De todo modo, o Movimento Circulista fundaria uma frente trabalhista cristã, discutida e programada durante um congresso eucarístico, em Belo Horizonte, em 1936, e sua estrutura organizacional precederia àquela da Confederação Nacional dos Operários Cristãos - CNCO. Os objetivos maiores dessa frente estavam, evidentemente, na disseminação do movimento via formação de organismos de base os círculos operários - que pudessem propagandear sua doutrina e influenciar organicamente a vida sindical.

A doutrina circulista é muito simples e de fácil absorção. As suas bases foram sistematizadas num documento intitulado "Manual dos Círculos Operários", cuja primeira edição data de 1948, tendo tido inúmeras reedições ao longo do período da redemocratizaçã.o do país. Esse manual, escrito em linguagem simples e direta, expõe os princípios doutrinários e de organização do movimento, como se desenvolve em sequência.

O manual pontifica cinco princípios fundamentais. De saída define-se diante do conflito de classes, repudiando a "luta de classes" e situando os "círculos operários" enquanto instrumentos da paz social. Postula, por outro lado, a propriedade privada enquanto um direito natural, não questionável, mas que poderia ser relativizado pelo estado. Afirma, assim, a necessidade ela intervenção do Estado na "questão social", pelo que se aponta os conflitos de classes, para regular: salários, produção e preços. A questão tem a seguinte redação:

[...] O Estado não se deve limitar à tutelar os direitos e a ordem pública, mas fazer o possível para que as leis e instituições sejam tais que da organização do estado demane a prosperidade da nação e do indivíduo (Manual dos Círculos Operários, 1961, pag. 15)

Esta rejeição originária do liberalismo era postulada por um dos principais doutrinadores do movimento circulista mundial, o sociólogo italiano Toniollo, do seguinte modo: "[...] o trabalho cada vez mais dominante, a natureza cada vez mais dominada, o capital cada vez mais proporcionado[...]".

Essa tese do "trabalho proporcionado" permitia ao movimento, entre outras questões, levantar a bandeira da defesa da pequena propriedade contra a grande empresa, ou mesmo, no Brasil, fazer um discurso contrário ao latifúndio, ainda que se situando num abstrato plano de reformas necessárias. Fundado nas duas concepções, de um lado, crítica ao "estado totalitário", e de outro, "trabalho proporcionado", o circulismo formulava seu programa: lutar pelo "salário vital"; lutar pelos contratos coletivos de trabalho; pela participação dos operários no lucro das empresas; pela responsabilidade das empresas em relação à justiça social, o que as deveria levar a fundar associações operárias e cooperativas, assim como, batalhar pela sindicalização dos "empregados" (sic).

Estes três pontos de seu programa são detalhados no Manual, citado mais acima, apontando sua correspondência aos direitos da Consolidação das Leis do Trabalho - CLT - tais como: a defesa de uma "proteção" ao trabalhador rural e assinalando a necessidade de lutar por um "programa agrário". E, tal programa, pontificava a premência de que: se elaborasse leis sobre o arrendamento de terras, fixando, inclusive, um prazo mínimo de cinco anos para a vigência dos contratos de arrendamentos; planos de compra de terras pelo governo, em regiões próximas aos grandes centros, para 
vendê-las aos agricultores em longos prazos; necessidade de convencer os donos de terra a: produzir em suas terras, organizar cooperativas de credito e produção, e outras.

Finalmente, postulava-se a necessidade de fundar círculos operários nas zonas rurais para promover: "[...] a grandeza do trabalhador rural e a necessidade de amparo ao trabalho rural $[\ldots] "$ ".

A forma de organização circulista era similar à estrutura sindical brasileira: em sua base estavam os círculos operários, ou os núcleos, organização no âmbito local; na esfera estadual, os trabalhos eram comandados por federações e, finalmente, em âmbito nacional afunilava-se na coordenação da Confederação Nacional dos Círculos Operários. Segundo dados da própria CNCO, em 1949, o movimento já contaria com duzentos mil associados (LOYOLA, 1980) e tinha uma estrutura de núcleos e federações montadas nos seguintes nos estados: Rio Grande do Sul, Rio de Janeiro, São Paulo, Santa Catarina, Pernambuco, Paraíba, Ceará e Minas Gerais.

De todo modo, a questão do trabalhador rural seria objeto de discussões em alguns dos congressos desse movimento. Assim, no $3^{\circ}$ Congresso dos Círculos Operários do Brasil, em junho de 1940, recomendava-se a necessidade de organizar círculos operários entre os trabalhadores rurais, para o que se alertava a necessidade de contar com o apoio dos padres e das paróquias (CNCO, 1940). De modo similar, no $2^{\circ}$ Congresso Circulista de S.Paulo, advertia-se, também, a urgência de incentivar a organização dos trabalhadores rurais e, inclusive, diante do diagnóstico da dificuldade de formar círculos dentro das propriedades rurais, propunha-se a filiação dos trabalhadores rurais aos círculos municipais. Ainda, ponderando as barreiras representadas pela propriedade agrária, orientava-se para que os circulistas privilegiassem contatos com: padres, professores, farmacêuticos, fazendeiros, agrônomos e comerciantes. Somavam-se a essas orientações, um conjunto de proposições visando melhorar a qualidade de vida das populações rurais, tais como: programas de alfabetização para a população adulta, entre outras medidas sociais como: promover assistência médica e jurídica, fornecimento de insumos agrícolas, telefones, transportes, entre outras (FECOESP, 1948).

Pode-se afirmar que o movimento Circulista, dirigido pela CNCO, permaneceria, até os anos 60, enquanto um dos instrumentos políticos importantes de orientação e intervenção da Igreja Católica no movimento operário. Finalmente, sendo uma entidade de consultoria oficial do ministério do Trabalho, passaria a atuar na administração dos diversos serviços assistenciais que, então, se organizariam, entre os quais, Serviço Social do Comércio - SESC- e Serviço Social Rural do ministério da Agricultura.

Tais iniciativas de católicos, diversas em muitos pontos, acabariam por se unificar pela preocupação com as novas questões colocadas pelo início da politica trabalhista agrária. Desse modo, suas divergências perderiam peso diante do projeto de conquistar c controlar a estrutura sindical que, então se gestava.

\section{CNCO e Propostas Doutrinárias para o Movimento Popular (1960 a 1964)}

A evolução do Movimento Circulista no Brasil pode ser brevemente caracterizada pela consideração de algumas modificações em sua doutrina. E, a reorganização do movimento, a partir dos últimos anos da década de 50 , já seria uma consequência de tais inovações. Uma primeira mudança importante estaria na defesa de uma "reforma social", que se compreendia como caracterizando-se pela premência de alterar a "ordem" social, em termos sociais e institucionais, o que de modo coerente com seus princípios, projetava a necessidade de reformas que não 
tocassem na propriedade privada. Não chegava, portanto, a definir uma opção clara pelo reformismo agrário, e muito menos, a definir-se pela premência de reformas econômicas no país.

Ao contrário, a CNCO trataria de preparar uma liderança militante que pudesse intervir enquanto ativistas sindicais, a partir de um programa "anti comunista", "anti trabalhista", o que era considerado pelas outras forças políticas como um posicionamento pela defesa do status quo agrário. Desse modo, a CNCO, definiria como princípios de sua proposta de reforma os seguintes pressupostos brandos: a industrialização levantava estímulos poderosos, atrações violentas, o êxodo rural condicionava a necessidade de uma intervenção, ou seja, tais forças de atração deixadas livres poderiam vir a liquidar a agricultura. De acordo ainda com essa sua crítica moral à industrialização, posicionava-se contra o Estado brasileiro. Postulava a tese de que um dos males da questão social estaria na excessiva burocratização das atividades econômicas e sociais e que, mais particularmente, atingiam a estrutura sindical brasileira, considerada como uma correia de transmissão do Partido Trabalhista Brasileiro (CNCO, 1959)..

Tal reversão em seus apoios anteriores ao Governo brasileiro, se manifestaria, mais claramente, na convocação de uma assembleia nacional da $\mathrm{CNCO}$, em maio de 1960 e que colocava como questão principal o equacionamento dos problemas causados pelo empobrecimento dos operários, que atingia, conforme aquele documento, de modo especial, os trabalhadores agrícolas. Entre as resoluções dessa assembleia destacavam-se a necessidade de: expandir os princípios circulistas ao movimento popular; incentivar a formação de novos círculos operários e formar quadros de liderança sindical comprometidos com sua "reforma" e que se dispusessem a implantar a representação sindical para os trabalhadores rurais.

Seria, também, eleita nova diretoria para a $\mathrm{CNCO}$, que deveria preparar um grande congresso operário, a ser realizado na capital paulista, ainda em agosto daquele ano. Propunha-se a realizar um movimento de alfabetização que expandisse sua doutrina, assim como, mudanças organizacionais que possibilitassem a ampliação de sua atuação sindical.

Originariamente, a confederação estava dividida em três departamentos, a saber, formação social, divulgação e propaganda e ação sindical. Na nova estrutura proposta apontava-se a necessidade de proceder a novos aparelhamentos no departamento sindical, para que pudesse coordenar "campanhas sindicais" e planejar o combate à "infiltração comunista nos sindicatos".

Nesse sentido, o início da gestão de Padre Pedro Belisário Veloso, como novo assistente eclesiástico dos círculos, a partir de 1956, ensejaria uma reorganização dos trabalhos de formação que passariam a ser coordenados pelo Instituto Superior de Formação Operária - ISUFO - e pela Escola de Liderança Sindical - ELO. Aquele assistente eclesiástico estreitaria, também, os vínculos de sua entida de com o Instituto de Estudos Políticos Econômicos e Sociais da Pontifícia Universidade Católica - PUC do Rio de Janeiro e com a Escola Superior de Administração e Negócios da Ação Social, de São Paulo. Criava-se, por essa via, uma sustentação junto aos intelectuais do Serviço Social e outros, e fundava-se, também, uma infra- estruturas de pesquisa, de produção de dados e de reflexão.

Desse modo, os cursos de formação sindical, implantados em 1958, incluiriam, entre seus temas: questões de economia politica; direito constitucional; legislação do trabalho e previdência; questões sociais e, principalmente, inculcaria nos sindicalistas estudantes uma acirrada crítica ao marxismo e ao comunismo. Conhecidos como "cursos 
Elo", eram realizados na capital da República e, até abril de 1960, teriam sido realizados trezentos e sessenta e cinco cursos, formando algo como onze mil e duzentos e cinquenta sindicalistas circulistas (MANFREDI, 1996). Claramente, tratava-se de um período de alterações nos objetivos do movimento. Como se viu, a CNCO administrava uma estrutura de serviços sociais, que se estendiam, tanto para seus associados círculos, quanto para as populações "carentes" em geral. Na década de 60 ela passaria a se configurar como organismo de coordenação de uma intervenção especificamente doutrinária e prática no movimento sindical e operário.

Em junho de 1961, por exemplo, patrocinaria o "Encontro Nacional de Movimentos de Renovação Sindical", realizado em São Paulo e que reuniria seus representantes dos estados de São Paulo, Minas Gerais, Guanabara e Bahia, assim como, representantes de outros movimentos sindicalistas dos estados de Rio de Janeiro, São Paulo e Rio Grande do Sul. Tal encontro, realizado no Teatro Oberdan, na capital de São Paulo, projetaria a união de diversas tendências sindicais em torno dos objetivos do circulismo (CNCO, 1961).

Esta união de correntes passaria a desenvolver uma espécie de intervenção orgânica, o que pode ser ilustrada por alguns episódios. Um "Congresso Sindical Nacional", realizado no Rio de Janeiro em setembro de 1961, noticiaria que estavam presentes 300 líderes sindicais democratas cristãos contra 1.000 representantes do sindicalismo esquerdista. Formava-se, assim, uma frente que tinha como programa a luta Pelo sindicalismo livre, com as seguintes bandeiras: sindicalismo independente, sem imposto sindical e sem política partidária; defesa dos contratos coletivos de trabalho e pela formação de sindicatos por empresas e, finalmente, voltada para o desenvolvimento de uma estratégia para a formação dos sindicatos de trabalhadores rurais. Nesse rumo, seus princípios políticos básicos seriam lutar: contra "a corrupção sindical", contra "os pelegos vermelhos" e contra os sindicalistas amarelos (os sindicalistas ligados ao Ministério do Trabalho) (CNCO, 1961).

Neste sentido, a formalização de uma direção colegiada e de um conselho diretor nacional, composto pelas seguintes entidades circulistas: CNCO, Federação dos Círculos Operários do Estado de São Paulo, Movimento de Renovação Sindical de São Paulo entre outros, apontava para uma intervenção mais orgânica e que não me parece poder ser simplesmente atribuída a circunstâncias de disputa de eleições para a presidência da República, que então se realizava. Tais posicionamentos e políticas de frente consolidaram-se nos debates travados no " $8^{\circ}$ Congresso Nacional dos Círculos Operários", realizado em São Paulo, em junho de 1962, quando se comemorava $25^{\circ}$ aniversário do circulismo. Nesse congresso, preparava- se uma campanha para divulgar tais alianças, tal como se faria com o lançamento do Movimento Sindical Democrático, em julho daquele mesmo ano.

Perdida a possibilidade, na década de 30 , de controlar o movimento sindical operário e estabelecer um sindicalismo operário de bases cristãs, o movimento circulista operava para implanta-lo e, principalmente, estende-lo aos camponeses e trabalhadores rurais. Sugere-se que a década de 60 demarcaria a tentativa da CNCO de forjar um sindicalismo urbano contrário ao trabalhismo e essa politização em bases cristãs do movimento operário, teria no estado de São Paulo seu exemplo paradigmático.

\section{A Fecoesp e os Sindicatos de Trabalhadores Agrícolas}

A Federação dos Círculos Operários do Estado de São Paulo - FECOESP - ao lançar-se numa campanha de sindicalização rural, seguiria os novos rumos da política 
sindical deflagrada pela frente $\mathrm{CNCO}$ e Movimento de Renovação Sindical. Enquanto programa especificamente rural, definia-se uma estratégia simples que privilegiava a organização de sindicatos por regiões administrativas da Igreja, ou seja, aquela estrutura de base já instalada pela Igreja. Apenas após completado esse trabalho se partiria para atuações sindicais em âmbito municipal (CNCO, 1962).

A primeira diocese escolhida seria a de Presidente Prudente, onde o bispo Dom José Aquino Pereira emprestaria seu apoio à iniciativa. Desse modo, em 1961, seria fundada a Associação Profissional de Trabalhadores Rurais de Presidente Prudente Tal associação seria um marco para este movimento que, então, se estenderia às Dioceses de Lins, de Juquiá e outras (FECOESP, 1962)

A importância em termos nacionais do plano sindical de São Paulo para o conjunto do movimento circulista, pode ser ponderada quando se considera que suas orientações passaram a compor o programa nacional de sindicalização rural da CNCO. Inovando, nessa orientação, a Fecoesp criaria, em 1962, um departamento específico para a sindicalização rural. Mobilizando seus quadro sindicais urbanos, contando com o apoio de alguns setores empresariais, contando com a estrutura das organizações de base da Igreja, como por exemplo, os "Congregados Marianos", a "Ordem de São José", "Filhos de Maria" e outras, este movimento atingiria o interior do estado de São Paulo. Até 1962 tinham sido fundadas quarenta e nove associações pré-sindicais, sendo que onze delas seriam reconhecidas como sindicatos pelo Ministério do Trabalho e Previdência Social (CNCO, 1962).

O processo de formação de sindicatos era sumário. Anunciava- se, nas regiões alvos, a realização de assembleias de fundação do sindicato rural, convocavam-se as organizações de base da Igreja, que constituiriam a massa de trabalhadores rurais sócios fundadores dos sindicatos. Passava-se a expor os objetivos do sindicato que se pretendia criar e se formava uma diretoria para a nova entidade. Conforme dirigente sindical rural paulista:

[...] Nós tínhamos a rádio do trabalhador rural, com o programa "Trabalhador Rural Avante", retransmitida, senão me engano, pela Record, funcionava em Tremembé. Tinha notícias dos sindicatos, presidentes de sindicatos davam entrevistas. [...] Visitávamos esses lugares, fazíamos contatos, geralmente o vigário da paróquia dava muita cobertura. Nessas regiões visitadas por nós, sempre ficava um representante, ou o vigário, ou representantes dos círculos operários [...] (conforme entrevista concedida à autora, pesquisa Sindicalismo Rural em São Paulo: origens da Fetaesp, CNPq, 1981-1982).

Ainda assim, a ação sindical obedecia a algumas orientações estratégicas, como se segue. Conforme entrevista de um militante dos círculos que se tornaria "sindicalista profissional" desde que era funcionário da $\mathrm{CNCO}$ e tinha em seu currículo a participação na fundação de muitos sindicatos, entre os quais, cita, especificamente, o sindicato dos metalúrgicos e dos eletricitários, em finais da década de 40, em S.Paulo:

[...] a convite de Frei Celso Maria de São Paulo, nós estabelecemos um esquema de atividades e partimos para nossas regiões, fundando sindicatos na Noroeste, na Araraquarense, na Alta Paulista. Estávamos envolvidos eu, Monsenhor e Franco Baruzelli, que hoje e" deputado. Nas regiões em que existiam os Círculos Operários e que se fundavam sindicatos, aí os presidentes das Congregações Marianas passavam a ser os presidentes dos sindicatos. Mas esses sindicatos eram para defender os 
trabalhadores do Comunismo [...]" (conforme entrevista concedida à autora, pesquisa Sindicalismo Rural em São Paulo: origens da Fetaesp, CNPq, 1981-1982)

Tais etapas no processo de fundação de sindicatos se orientavam por novas disposições ministeriais, que teriam aberto mão de alguns procedimentos correntes para o sindicato urbano, como por exemplo, a necessidade de fundar entidades présindicais, para depois então, pleitear o seu reconhecimento. Na intenção de implantar o movimento sindical, os circulistas privilegiavam a fundação de entidades de cúpula sindical, ou seja, fundados cinco sindicatos podia- se fazer o pedido de reconhecimento das "federações". Ainda assim, esse movimento se apresentava como representante da luta contra a "tutela" sindical e pelo sindicato livre.

No entanto, a sua luta pelos camponeses esbarrava em seus próprios compromissos doutrinários, como por exemplo seria o caso de seus posicionamentos contrários à reforma agrária. A posição adotada pelos Círculos Operários paulistas ilustra o que se afirma. No seu primeiro manifesto, o Círculo Operário de Lins defendia a reforma agrária, desde que as terras a serem desapropriadas tivessem uma justa indenização em dinheiro, de acordo com o valor da terra e sem alterar a Constituição da República (Manifesto do Círculo Operário de Lins, 1961.

Trata-se, a seguir, de caracterizar o processo de formação pelo qual passavam seus quadros sindicais, para, finalmente, poder fazer algumas apreciações mais conclusivas sobre a contribuição dessa corrente ao movimento sindical de trabalhadores rurais.

\section{Formação Sindical}

Este movimento tinha uma escola sindical, centro de formação de liderança sindical, localizada na cidade de Jacareí, com o nome de São Jorge, onde realizava seus cursos. Segundo a FECOESP, teriam sido realizados doze cursos de formação pelos quais passaram algo como quase trezentos militantes circulistas (FECOESP, 1962).

Tratando-se de um movimento laico, tinha sua orientação doutrinária a cargo de um assistente eclesiástico, na figura de Frei Celso Maria de São Paulo, personalidade maior e reverenciada pelo movimento. Caberia aquele frei cuidar do bom uso da doutrina, assim como, orientar o desempenho da formação.

Essa experiência de orientação doutrinária daria origem a um manual de formação sindical, que detalhava conteúdos e procedimentos a serem usados. Os cursos tinham, assim, seus procedimentos normatizados e definidos em detalhes, estabelecendo os temas e o número de aulas, como se segue. Na primeira aula, tratava-se de explicar as bases organizativas do movimento circulista e de sua estrutura nacional; a segunda aula introduzia os militantes nas técnicas de dinâmicas de grupo e liderança, ensinando como montar e dirigir reuniões de massa; na terceira aula se tratava de introduzir o aluno à hierarquia do movimento circulista, destacando-se as distinções entre dirigente, militante e subdelegados (estes últimos responderiam pelo movimento em sua área geográfica de atuação); a quarta aula discorria sobre a organização sindical do país, chamando a atenção para o fato de que os sindicatos rurais prescindiam da prévia formação de entidades pré-sindicais, sendo possível logo após a primeira reunião de base, entrar-se com pedido de reconhecimento junto ao Ministério do Trabalho.

A seguir, expunha-se as principais tendências do sindicalismo a nível internacional, assim como, suas ramificações no Brasil e apontava-se a Central 
Internacional das Organizações Sindicalistas Livres - CIOSL - enquanto aquela que os circulistas deveriam respeitar e seguir.

Caracterizava-se, especificamente, as principais centrais sindicais brasileiras, destacando as respectivas posições políticas e ideológicas, sendo que as distinguia em dois grandes blocos, de um lado, os comunistas e de outro as não comunistas. Destaque especial e elogios merecia o Movimento de Renovação Sindical. A quinta aula tratava da questão social e a sexta aula versava, com todos os detalhes, sobre os mecanismos de preparação de uma assembleia e de discussão em público, sendo que a sétima aula introduzia o aluno nas artes da oratória (FECOESP, 1963).

Sem dúvida, os objetivos principais de tal movimento estavam no controle das organizações trabalhistas no campo paulista. Deste modo, em julho de 1962, seria fundada a Federação dos Trabalhadores Rurais do Estado de São Paulo. Seguia-se, portanto, as orientações estratégicas da CNCO que pretendia conquistar a estrutura sindical de trabalhadores rurais. Os sindicatos de Trabalhadores Rurais - STR de Lins, de Assis, de Guariba, de Juquiá, de Matão e de Porto Feliz pleitearam a fundação da federação que seria reconhecida em 17 de agosto de 1963, por portaria do Ministro do Trabalho, Amauri Silva.

Em conclusão, na década de 60, o circulismo se expandiria para todo o país, através da Escola de Líderes Operários, sob a direção de Padre Pedro Belisário Veloso. Essa corrente sindical obteria apoio de diversas entidades sindicais internacionais, tais como: Confederação Latino Americana de Sindicatos Cristãos - CLASC- e outras. Formaria, então, uma frente com o "Instituto de Cultura do Trabalho" - ICT- que era apoiado pelo sindicalismo norte americano e dirigido por Freitas Marcondes, funcionando na capital paulista.

De todo modo, um militante resumia, nos seguintes termos, os resultados a que se chegara:

[...] Esta primeira experiência (dos cursos Elo, LMS) teve resultados que cedo se fizeram sentir no campo sindical. Ali, pela primeira vez no Brasil, os líderes comunistas se defrontaram com líderes portadores de uma ideologia e de um programa de ação que, sem compromissos com o peleguismo, representavam a verdadeira autenticidade sindical. $\mathrm{O}$ êxito da primeira experiência despertou o interesse da ACO, Ação Católica Operária, e com o apoio de muitos bispos começaram a proliferar as Elos, hoje em número de dez, em diversos Estados da Federação. [...] (FARIA, 1964: 142).

\section{Outras Propostas Sindicais da Igreja}

Em resposta à campanha da Conferência Nacional dos Bispos do Brasil CNBB - pela sindicalização rural, conforme seu Plano de Emergência, 1962, inúmeros planos e programas seriam iniciados em várias dioceses, como por exemplo, a formação da Frente Agrária Gaúcha no Rio Grande do Sul. Outras propostas sindicais rurais também seriam fundadas e, entre as mais importantes, deve-se mencionar o "Projeto de Natal", no Rio Grande do Norte, o projeto do Serviço de Orientação Rural dirigido pelo padre Paulo Crespo, entre os mais sistematizados.

O "Projeto de Natal" tem suas origens nas iniciativas de trabalho social do Secretariado Arquidiocesano de Ação Social, fundado em 1949, na diocese de D. Eugênio Sales. Fortes investimentos de trabalho por parte da Juventude Católica, levariam a que se formassem duas intervenções diferenciadas, a saber, a "missão rural" e o "centro de treinamento de lideres". De todo modo, o caráter contínuo do trabalho levaria a que a experiência se consolidasse e no ano de 1958, seriam realizadas 
as primeiras experiências de uma intervenção educativa através do rádio, formando-se as primeiras "escolas radiofônicas" para educação de base. E, em 1961, a diocese, através do Serviço de Assistência Rural - SAR - iniciaria trabalhos específicos de sindicalização rural (CAMARGO, 1971).

Mais articulado ao circulismo, o Serviço de Orientação Rural - SORPE - dirigido por padre Paulo Crespo, pároco de Jaboatão, seria fundado, em 1961, a partir de sua aliança com o Movimento de Renovação Sindical. Teria, entre algumas de suas iniciativas, juntamente com padre Paulo Mello, a realização do " $1^{\circ}$ Congresso de Lavradores e Trabalhadores Rurais do Nordeste", realizado em Itabuna, na Bahia, em junho de 1962. De todo modo, Padre Crespo justificava a fundação do Sorpe do seguinte modo:

[...] As Ligas Camponesas se tornaram propulsoras de uma revolução importada, estrangeira, cubana, com graves repercussões na vida nacional e internacional [...] o movimento sindicalista rural é a última esperança do homem do campo que perfaz $75 \%$ da população nordestina. [...] (CRESPO, 1963:60).

Assim, o SORPE surgiria como uma espécie de coordenação estadual do Projeto de Natal, que teria, por sua vez, a adesão de mais nove estados do nordeste. Fundado em certo planejamento, a ação pelo sindicato, estruturava-se numa divisão do estado em oito regiões, através das quais se deslocavam as equipes de formadores e de animadores rurais. Mapeada uma região, via contatos e informações, faziam-se duas intervenções sucessivas, a saber, campanhas de esclarecimento sobre o programa, junto a: vigários, estensionistas, agrônomos e professores e, na sequência, realizava-se um primeiro curso de formação para o camponês e trabalhador rural. Conforme ainda padre Crespo, após uma semana de treinamentos e aulas, em que se utilizava técnicas de dinâmica de grupo e de formação de lideranças, fornecia-se informações sobre a importância do sindicato rural, e, principalmente, selecionava-se aquelas pessoas que melhor se enquadrassem no perfil pretendido. Tais líderes rurais passariam por mais dois treinamentos, durante três meses, após o que seriam, então, fundados os sindicatos. Paulo Crespo (CRESPO, 1963: 64), avaliando tais trabalhos situaria que resultara na fundação, até meados de 1963, de setenta e sete sindicatos, em que trinta e três sindicatos tinham sido reconhecidos pelo MTPS e quarenta e quatro aguardavam reconhecimento.

A modo de uma conclusão, pode-se afirmar que o trabalho sindical oficialmente liderado pela Conferência Nacional dos Bispos do Brasil teria ressonâncias no Ministério do Trabalho Previdência Social. Explica-se, assim, de um lado, porque teria se formado com tamanha celeridade os cinqüenta sindicatos rurais e, de outro lado, porque apenas tais sindicatos de trabalhadores rurais seriam oficializados por aquele ministério. Este processo fundaria sindicatos nos estados: de São Paulo, Rio Grande do Norte, Rio Grande do Sul, Pernambuco, Paraíba, Ceará, Sergipe e Piauí.

\section{Ação Católica, Movimento de Educação de Base e os Sindicatos}

Inicio essa parte, dando a palavra a um dos coordenadores do Movimento de Educação de Base, da Equipe de Pernambuco. Trata-se de Waldemarin Wanderley. Para ele, o MEB iniciaria um trabalho de sindicalização rural com a motivação específica de combater a proposta da CNBB.

Avaliando o trabalho sindical no Nordeste, Wanderley (1984:280) agrupa algumas dessas iniciativas como coordenadas e articuladas ao Projeto de Natal, sendo que todas elas iniciariam seus trabalhos em 1961. Além do projeto do Sorpe, cita também a Equipe 
de Sindicalização do Secretariado de Planificação da arquidiocese de Teresina, assim como, a Equipe de Sindicalização da Paraíba e, finalmente, o SORAL Serviço de Orientação Rural de Alagoas.

Wanderley (1984:281) avalia esse trabalho e num breve resumo do modo de operar destas equipes, afirma:

[...] O processo implementado por esses grupos cristãos era de divulgar a importância do sindicato em programas radiofônicos, em seguida formar líderes em cursos e treinamentos, e em etapa final funda-lo, acompanhando-o em seu funcionamento posterior[...].

Ainda, conforme Wanderley, esse trabalho sofreria uma crítica da coordenação do Movimento de Educação de Base, que decidiria, em encontro de coordenadores, em Recife em 1962, liderar, também, um trabalho alternativo de sindicalização rural. Conforme Wanderley ( 1984: 285):

[...] vários fatores convergentes influíram na necessidade do MEB dedicar atenção especial à sindicalização rural: o estímulo dos bispos à sindicalização rural e o Plano de Emergência da CNBB, as diretrizes da Mater et Magister e outros[...] quando o Encontro de Coordenadores de Recife faria uma orientação específica sobre a questão[...]

Citando um relatório do "encontro de coordenadores do MEB", afirma que o MEB, orientava-se, portanto, pela necessidade de criticar o trabalho da CNBB e do clero, posto que: [...] visavam chegar na frente dos comunistas e há um perigo real de se imprimir uma orientação anti comunista [...] Wanderley, 1984: 286.

Ao que conclui que se estavam fundando sindicatos cristãos e que, portanto, se deveria condenar o envolvimento direto dos padres no sindicato rural, posto que:

[...] há uma organização originada de fora para dentro e uma orientação fundada em princípios doutrinários e ideológicos que marcaram a ação dos grupos assessores, induzindo os sindicalizados a terem posições motivadas por divergências que não eram suas. As equipes dos secretariados das dioceses tinham suas posições fundadas na doutrina da Igreja, orientações do bispo local e transmitiam uma formação confessional $[\ldots]$.

\section{Breves Questões Políticas na Fundação da CNBB}

O deslocamento do modelo italiano de intervenção prática da Igreja Católica no Brasil teria uma dívida importante com D. Helder Câmara e D. Jose Távora. Esse novo modelo se delinearia com a nomeação de D. Helder para a assistência nacional da Ação Católica, em 1947. Desse modo, para Souza (1984) a construção de um ativo movimento que se propunha a atingir todos os setores e classes da sociedade nacional, e não mais centrado exclusivamente na classe operária, situaria aquela igreja em novos tempos. Relativizava-se, por essa via, o peso da hierarquia na tomada de decisões, o que permitiria nuançar o peso daquelas instituições nos movimentos católicos (SOUZA, 1984).

Esse seria, ainda conforme Souza (SOUZA, 1984: 63) o caminho seguido pela Conferência Nacional dos Bispos do Brasil - CNBB, fundada em outubro de 1952.

[...] D.Hélder e D. José Távora, bispos auxiliares do Cardeal Câmara no Rio de Janeiro, ambos irão organizar a CNBB [...] É muito significativo 
que uma organização da hierarquia tenha tido como ponto de partida e base concreta a organização de movimentos leigos [...]

Como se sabe, a longo prazo, a CNBB encamparia os trabalhos de educação popular que então se desenvolviam e receberia do Governo brasileiro apoio e financiamentos, assim corno, concessões para o uso da radiofonia. Tais programas teriam, inicialmente, o apoio de Juscelino Kubitschek e resultariam na formulação de diretrizes nacionais pela Conferência Nacional dos Bispos, o que redundaria na fundação do Movimento de Educação de Base.

No entanto, o percurso dos programas radiofônicos se ampliaria muito além dos processos educativos e de desenvolvimento de comunidades, como eram os projetos pioneiros de Natal, no Rio Grande do Norte e os programas montados pela diocese de Aracaju, com o arcebispo D. José Távora.

Apenas considerando-se esses dois programas de alfabetização é possível situar, ao menos preliminarmente, as diferentes concepções que compunham o grande "guarda chuva" formado pelo MEB. O programa da diocese de Aracaju se caracterizava por sua abertura a novas perspectivas e pela confiança no desenvolvimento politico das comunidades camponesas. Sua cartilha de alfabetização "Viver é Lutar", documento base adotado pelo MEB, pode ilustar um posicionamento crítico e questionador da ordem social. Conforme trecho citado por Souza (SOUZA, 1984: 66) compunha a cartilha o seguinte trecho onde a Igreja se posicionava pelos direitos dos camponeses:

[...] Que Deus nos guarde de que a Igreja de hoje, e ainda mais a de amanhã, possa aparecer aos olhos das gerações de camponeses como um freio, como um entrave à justa promoção que o camponês está alcançando por meios legítimos [...].

Tais experiências pioneiras de educação de base através do rádio estruturadas pela CNBB teriam a seguinte evolução: em 1961 contaria com onze sistemas radiofônicos, que triplicariam no ano seguinte, alcançando o número de cinquenta e nove, já em 1963 (WANDERLEY, 1984). Assim, em 1964 existiriam sete mil e trezentas e cinquenta e três escolas e que atingiam a cento e oitenta mil alunos Por outro lado, durante o governo presidencial de João Goulart seriam utilizadas as concessões radiofônicas e consolidada a competência (específica do MEB para a promoção da educação popular) (ARANTES e LIMA, 1984).

Assim, o MEB desenvolveria seus trabalhos de conscientização, indo muito além dos ensinamentos da educação formal e da alfabetização via programas radiofônicos. Valorizando a cultura popular, os membros da Juventude Universitária Católica e Juventude Estudantil Católica promoviam cursos de formação de "animação popular"- ANPO- e espetáculos de teatro, entre outros. Assim, as atividades das ANPOS implicavam em estruturar a comunidade com a qual trabalhavam, a partir de colocar "como projeto" as suas principais reivindicações, carências e problemas. Conforme Wanderley (1984: 28):

[...] a animação popular visava levar a comunidade a superar seus problemas sociais, econômicos, culturais, políticos e religiosos, no sentido de afirmação de seus membros como sujeitos sociais [...]. 


\section{Ação Popular e Sindicatos de Trabalhadores Agrícolas}

Resultando dos conflitos da Juventude Universitária Católica com a hierarquia da Igreja, seria fundado um partido político - Ação Popular - que congregava tais setores divergentes. No entanto, a data exata de sua fundação é questão polêmica na bibliografia sobre o tema. De todo modo, alguns autores e ex militantes daquele partido situam duas datas para essa fundação, a saber: início de 1962 ou início de 1963. Claro que as datas não são fundamentais, mas que ajudam isto sim. No entanto, independente do desacordo quanto a datas, há uma convergência de nossos autores quanto ao sentido maior da fundação da AP, que afirma uma busca de autonomia frente à Igreja. Assim para Souza (1984: 153):

[...] No início de 1962, num encontro em Belo Horizonte, jovens jesuítas e da Juventude Estudantil Católica e mais alguns intelectuais e políticos, teceriam o eixo doutrinário para sua agremiação independente e longe dos ditames da instituição da Igreja [...] Elege-se uma coordenação, para organizar aquele movimento que ficaria conhecido como Grupão [...]

E conclui: [...] apenas em março de 1963, com o encontro nacional do Grupão é que o movimento se consagraria como Ação Popular [...]Partia-se, na formação da AP, de um debate ideológico em que a famosa "questão da consciência histórica", tal como ficaria conhecida, teria um papel destacado. Trata-se da tese política elaborada pelo padre Henrique de Lima Vaz, dos quadros da Pontificia Universidade Católica do Rio de Janeiro - PUC-RJ e assistente eclesiástico da jUC. Essa tese, debatida no encontro de 1962, seria um divisor de águas. Partia da afirmação do homem em sua relação com a materialidade, o que levaria a uma oposição entre ele e o mundo, ou seja, o mundo espaço do imediato- funcionaria como instrumento de imposição de consciências umas sobre as outras. No entanto, em seus desenvolvimentos levaria a uma reconciliação, quando o mundo, então, se tornaria um instrumento de comunicação entre as consciências. Concluía-se, então, que o movimento da história caminharia na direção de um movimento de libertação das consciências subjugadas e, portanto, o movimento da história caminharia na direção de um movimento de libertação. Essa dialética hegeliana levantava a questão da necessidade de uma intervenção prática no mundo.

De todo modo, o novo partido se definia pela necessidade histórica do socialismo, postulando que na nova etapa do "neo Capitalismo", a proletarização da classe média e a incapacidade histórica da burguesia, colocavam, entre outros fatores, a necessidade de mobilizar o povo para cumprir "o seu papel libertador". A busca de tais objetivos colocava a necessidade de organiza-lo e conscientiza-lo para lutar contra a dominação capitalista "nacional e internacional", assim como, contra a "dominação feudal"( WANDERLY, 1984: 402).

Completando esta breve introdução, caberia destacar outra interpretação. Arantes (1984) coloca que a segunda reunião de fundação da AP ocorreria em Belo Horizonte, em junho de 1962, destacando a representatividade do encontro que já contaria com delegados de quatorze estados da federação.

No que se refere a sua trajetória, ao longo de seus dois anos de vida legal, 1962 a abril de 1964, a Ação Popular se caracterizaria pela forte presença na vida pública nacional. Nesse sentido, para Wanderley (1984: 487) alguns fatores explicariam a sua combatividade e presença no cenário politico nacional. Mas entre eles, principalmente, estaria o fato de que se desligando da Ação Católica Brasileira, a Juventude Universitária Católica e a Juventude Estudantil Católica levariam consigo uma estrutura organizacional 
montada nacionalmente, seja na forma de contatos políticos e de quadros políticos, seja na transferência de seus trabalhos concretos no setor de educação popular. Tais trabalhos da Ação Católica Brasileira se organizavam por redes de aderentes, entre os quais: operários, estudantes secundários, estudantes universitários, homens de ação, senhoras católicas, entre outros.

Desse modo, essa estrutura da Ação Católica Brasileira seria rachada e a AP passaria a contar com parte importante dessa rede nacional. Tratava-se, assim, de uma organização presente em diversas classes e setores da sociedade e, especialmente, tinha a liderança no movimento estudantil e universitário.

De todo modo, a coordenação nacional da Ação Popular estaria nas mãos de Herbert de Souza e compunham com sua direção as seguintes personalidades: Aldo Arantes, Luís Alberto Gomes de Souza, Haroldo Lima, Cosme Alves Neto, Duarte Pereira, Antônio Lins, Severo Sales, Péricles dos Santos, Maria Angélica Duro, Manuel Joaquim Barros e outros.

\section{Ação Popular e a Fundação de Sindicatos}

Para Wanderley (1984), os principais trabalhos políticos da Ação Católica que se transferiram de fato para a AP, seriam as equipes do Movimento de Educação de Base que trabalhavam a sindicalização e a educação popular. Tais trabalhos estariam sediados nos estados de: Sergipe, iniciado no ano de 1961; Maranhão, iniciado em 1962; na Bahia, também em 1962; assim como os trabalhos nos estados de Goiás e Minas Gerais.

Conforme Aldo Arantes (1984: 44), o trabalho de sindicalização rural da AP se desenvolveria colado às atividades sindicais do MEB, desde que seus militantes estavam engajados nas equipes de animadores e assessores rurais. Afirma que:

[...]Foi participando e ajudando as atividades do MEB, algumas da Superintendência da Política Agrária e diversas iniciativas independentes que a AP conseguiu relacionar-se com o movimento camponês e de assalariados rurais. Pôde contribuir com o processo de organização de trabalhadores agrícolas, não só quanto à fundação de sem número de sindicatos de trabalhadores rurais, como também nas articulações para a fundação da entidade nacional [...] na fundação da Confederação Nacional de Trabalhadores Agrícolas - Contag, em 20 de dezembro de 1963. Nesta ocasião a AP tinha sob sua influência oito federações estaduais[...].

Quase finalmente, registre-se que a política de "frente única" que tivera sucesso na condução do movimento universitário seria, ao menos em parte, estendida para os trabalhos de fundação de sindicatos. Conforme Arantes ( 1984: 45):

[...] No congresso de fundação da Contag a AP fez aliança com o PCB, com base na política de defesa das reformas e da reforma agrária, e para isolar o grupo mais direitista que se apresentou no Congresso[...]

Finalmente, cabe colocar em relevo outra informação daqueles autores. Conforme eles, o trabalho da AP teria construído uma ponte entre a proposta do sindicato e as "ligas camponesas", trazendo, assim, muitas ligas para dentro da estrutura sindical que, então, se criava.

De todo modo, em Minas Gerais, sob a influência desse trabalho, teriam sido fundados algo como cem sindicatos de trabalhadores rurais. Por outro lado, na Zona 
da Mata de Pernambuco, esse trabalho sindical conseguiria forte aproximação com as Ligas Camponesas, conseguindo a adesão de algumas delas para o programa de reconhecimento de sindicatos levado a efeito pelo governo de Miguel Arrais. No entanto, um caso interessante também seria a atuação da AP na fundação do Sindicato de Trabalhadores Rurais de Pindaré Mirim que lideraria um movimento de posseiros e pequenos produtores contra as arbitrariedades dos grandes criadores e gado.

\section{Referências}

ARANTES, Aldo e LIMA, Haroldo História da Ação Popular: da JUC ao PC do B SP: Edi Alfa Ômega, 1984

CAMARGO, Cândido P. Igreja e Desenvolvimento,_SP: Edi Cebrap, 1971

CNCO Anais do III Congresso Nacional dos Círculos Operários do Brasil, RJ: Confederação Nacional dos Círculos Operários - CNCO, RJ:1940

CNCO Boletim,_abril de 1959, RJ: CNCO

CNCO Boletim, julho de 1959, RJ: CNCO

CNCO Boletim julho de 1960, RJ: CNCO

CNCO Boletim, junho de 1961, RJ: CNCO

CNCO Boletim,_janeiro/fevereiro de 1962, RJ: CNCO CNCO Boletim_setembro de 1961, RJ: CNCO

CNCO Manual dos Círculos Operários, Rio de Janeiro: Edições da Confederação Nacional dos Círculos Operários, 1961

CRESPO, Paulo "O Problema Camponês no Nordeste do Brasileiro", in revista Síntese Política Econômica e Social, n ${ }^{\circ}$ 17, jan/março 1963, Instituto de Estudos Políticos e Econômicos e Sociais, PUC-RJ, RJ: 1963

FARIA, Octávio Sindicalismo Novo, in revista Síntese Política, Econômica e Social, $\mathrm{n}^{\mathrm{O}}$ 22, abril/junho de 1964, Instituto de Estudos Políticos e Econômicos e Sociais, PUC- RJ, RJ: 1964

FECOESP Anais do $2^{\circ}$ Congresso Nacional dos Círculos Operários do Brasil, Federação dos Círculos Operários do Estado de São Paulo - FECOESP, SP: 1948

FECOESP Relatório Anual_,SP: Federação dos Círculos Operários de São Paulo, 1962

FECOESP Curso de Liderança Sindical_São Paulo: Edi. Saraiva, 1963

LOYOLA, M. Andréia Os Sindicatos e o PTB: um estudo de caso em Minas Gerais. Petrópolis: Vozes/Edi. Brasileira de Ciências, 1980

MANFREDI, Silvia Maria Educação Sindical: entre o Conformismo e a Crítica. São Paulo: Edi. Loyola, 1986

MANFREDI, Silvia Maria Formação Sindical ( História de Uma Prática Cultural) no Brasil, São Paulo: Escrituras Edi., 1996.

MARTINS, José de Souza "Os Camponeses e a Política", in MARTINS, IS Os Camponeses e a Política no Brasil. Rio de Janeiro: Edi. Vozes, 1981.

MEDEIROS, Leonilde Sérvolo A Questão da Reforma Agrária no Brasil: 1955-1964, 
Dissertação de Mestrado, Faculdade de Filosofia e Ciências Humanas da USP, SP, 1982, datilo.

MEDEIROS, L. S. Lavradores, trabalhadores Agrícolas. Camponeses: os comunistas e a constituição de classes no campo, tese de Doutorado em Ciências Sociais, IFCH, Unicarnp, Campinas, 1995 ( micrado).

PAIVA, Vanilda Igreja e Questão Agrária.São Paulo: Edi. Loyola, 1985.

REYMOND, Delcy Uma experiência de Serviço Social na Federação dos Círculos Operários de São Paulo. Monografia de Conclusão de Curso, Escola de Serviço Social, SP, 1958 ( datilo).

SEGATTO, José Reforma e Revolução: as vicissitudes políticas do PCB, 1954-1964, tese de Doutorado em História, FFCL, USP, SP: 1993 ( mimeo).

SOUZA, L.A G. A JUC: os Estudantes Católicos e a Política. Petrópolis: Vozes, 1984.

VIANNA, L J Werneck Liberalismo e Sindicato no Brasil. Rio de Janeiro: Paz e Terra, 1976.

VANDERLEY, Luis Eduardo Waldemarin Educar para Transformar: Educação Popular. Igreja Católica e Política no MEB. Petrópolis: Vozes 1984.

Notas

' Professora Senior, Pesquisadora do CNPq, voluntária no Programa de Pós-graduação em Ciências Sociais, Unesp de Araraquara. leilastein@terra.com.br

Recebido em abril-13

Aprovado em maio-13 